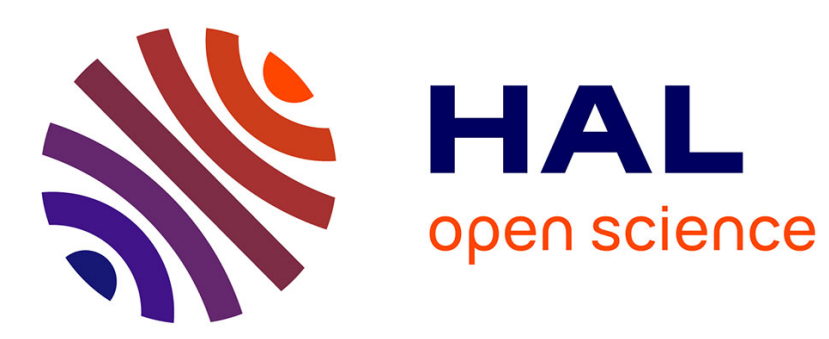

\title{
ESTIMATING INDIVIDUAL FITNESS IN THE WILD USING CAPTURE-RECAPTURE DATA
}

Olivier Gimenez, Jean-Michel Gaillard

\section{To cite this version:}

Olivier Gimenez, Jean-Michel Gaillard. ESTIMATING INDIVIDUAL FITNESS IN THE WILD USING CAPTURE-RECAPTURE DATA. Population Ecology, 2017. hal-03502427

\section{HAL Id: hal-03502427 \\ https://hal.science/hal-03502427}

Submitted on 25 Dec 2021

HAL is a multi-disciplinary open access archive for the deposit and dissemination of scientific research documents, whether they are published or not. The documents may come from teaching and research institutions in France or abroad, or from public or private research centers.
L'archive ouverte pluridisciplinaire HAL, est destinée au dépôt et à la diffusion de documents scientifiques de niveau recherche, publiés ou non, émanant des établissements d'enseignement et de recherche français ou étrangers, des laboratoires publics ou privés. 
ESTIMATING INDIVIDUAL FITNESS IN THE WILD USING CAPTURE-

$6 \quad{ }^{1}$ Centre d'Ecologie Fonctionnelle et Evolutive (UMR 5175), CNRS-Université de

7 Montpellier - Université Paul-Valéry Montpellier - EPHE, campus CNRS, Montpellier cedex

8 5, France

$9 \quad{ }^{2}$ E-mail: olivier.gimenez@cefe.cnrs.fr (tel: 0033467613314)

$10{ }^{3}$ Laboratoire Biométrie et Biologie Evolutive UMR 5558, Bât. 711 Université Claude Bernard

11 Lyon 1, 43 Boulevard du 11 Novembre 1918, 69622 Villeurbanne Cedex-France

$12 \quad{ }^{4}$ E-mail: jean-michel.gaillard@univ-lyon1.fr 
1 Abstract

3 The concept of Darwinian fitness is central in evolutionary ecology, and its estimation has

4 motivated the development of several approaches. However, measuring individual fitness remains

5 challenging in empirical case studies in the wild. Measuring fitness requires a continuous

6 monitoring of individuals from birth to death, which is very difficult to get in part because

7 individuals may or may not be controlled at each reproductive event and recovered at death.

8 Imperfect detection hampers keeping track of mortality and reproductive events over the whole

9 lifetime of individuals. We propose a new statistical approach to estimate individual fitness while

10 accounting for imperfect detection. Based on hidden process modelling of longitudinal data on

11 marked animals, we show that standard metrics to quantify fitness, namely lifetime reproductive

12 success, individual growth rate and lifetime individual contribution to population growth, can be

13 extended to cope with imperfect detection inherent to most monitoring programs in the wild. We

14 illustrate our approach using data collected on individual roe deer in an intensively monitored

15 population.

16

17 Keywords

18

19 Delifing $\bullet$ Growth rate $\bullet$ Imperfect detection $\bullet$ Lifetime reproductive success $\bullet$ Mark-recapture $\bullet$

20 State-space models. 
Introduction

3 Darwinian fitness is the Holy Grail of evolutionary ecologists. While it is well established that the

4 Malthusian parameter $(r)$ provides a reliable measure of the average individual fitness in a

5 population (Fisher 1930; Hamilton 1966; Lenski and Service 1982) in a deterministic environment,

6 how to best estimate the fitness of a given individual in the wild remains an open question. Several

7 estimates of individual fitness have been proposed, which differ mainly on whether they are single-

8 or multiple generation estimates and they incorporate or not the timing of reproduction (e.g.,

9 Brommer et al. 2002, 2004). Rate-insensitive fitness measures only account for the number of

10 offspring produced at some stage by a given individual during its lifetime. Two measures are

11 commonly used in field studies: first, the lifetime reproductive success (LRS; Clutton-Brock 1988;

12 Newton 1989) is the total number of offspring an individual has successfully raised at some age

13 (e.g., birth, 1 year of age) or stage (e.g., newborn, weanling/fledging, first reproducers); second, the

14 lifetime breeding success (LBS or $\mathrm{R}_{0}$ ) is the total number of offspring an individual has produced

15 soon after birth during its lifetime (e.g., Rose et al. 1998). On the other hand, rate-sensitive fitness

16 measures account for both the number of offspring produced at some stage by a given individual

17 during its lifetime and the ages at which these offspring have been produced. McGraw and Caswell

18 (1996) proposed an estimate of individual fitness ( $\lambda_{\text {ind }}$ hereafter) that includes both magnitude and

19 timing of survival and reproduction. As such, it has been argued to be a better estimate of fitness

20 than LRS (Käär and Jokela 1998). However, the $\lambda_{\text {ind }}$ metric has been criticized on the ground that

21 the mean of the $\lambda_{\text {ind }}$ does not match with the asymptotic population growth rate $(\lambda)$ calculated from

22 mean individual age-specific vital rates (Lenski and Service 1982) and that the timing of

23 reproduction is unrealistically accounted for since all offspring produced by a given individual

24 should reproduce at the very same age as their parent. Moreover, an empirical comparative analysis

25 of detailed data including pedigrees showed that LRS worked well in both short-lived and long- 
1 lived birds (Brommer et al. 2004). However, both LRS and $\lambda_{\text {ind }}$ are absolute measures, whereas

2 Darwinian fitness is a relative concept. To address this issue, Coulson et al. (2006) developed the

3 lifetime individual contribution (LIC) to population growth. This metric has the main advantages

4 over LRS to account for survival and fecundity components on the same scale and to be a relative

5 measure that is standardized for variation in population abundance.

Based on the empirical evidence, LRS, $\lambda_{\text {ind }}$ and LIC are the most commonly used metrics in

7 population studies of species in which individual reproductive success can be assessed directly from

8 observations, such as in most species of mammals and birds (see Clutton-Brock 1988 and Newton

91989 for case studies). This also includes human populations for which a continuous monitoring is

10 sometimes available from birth to death (Käär and Jokela 1998; Korpelainen 2000; Lahdenpera et

11 al. 2004; Moorad 2013). In the wild, individuals may or may not be detected (i.e., seen or captured)

12 at various times in their lifetime, which raises the issue of a detection probability less than one

13 (Lebreton et al. 1992; Nichols 1992). Ignoring imperfect detection can lead to flawed inference

14 about evolutionary questions, fitness estimation making no exception (Gimenez et al. 2008). First,

15 fitness components (survival and reproduction) are underestimated if the date of death of an

16 individual who was last encountered before the end of the study is wrongly assigned to the date it

17 was last observed. Second, estimates of fitness metrics come without any quantification of sampling

18 uncertainty related to the estimation of demographic rates. Third, dropping individuals for which

19 some reproductive and / or mortality events could not be recorded due to non-detection can lead to

20 biases in the estimation of fitness metrics. This is likely to be the case when the process leading to

21 miss individuals depends on their reproductive status. And last but not least, discarding individuals

22 with incomplete records results in smaller sample size and sub-optimal use of field data at the best,

23 and more likely corresponds to an additional source of bias because a lower probability of detection

24 is often associated with more cryptic behaviour typical of subordinates (e.g., Cubaynes et al. 2010).

25 Within vertebrate populations in the wild for which individual fitness data are currently available, 
1 we thus expect mean individual fitness to be over-estimated and measures of variance in individual

2 fitness to be under-estimated.

The purpose of this paper is to show how to obtain the three most commonly used fitness

4 metrics while coping with imperfect detection. We use multistate mark-recapture (MR) models

5 (Lebreton et al. 2009), which allow the estimation of survival and transition between reproductive

6 states, and incorporate latent states alive with associated number of offspring to infer fitness

7 metrics. We illustrate our approach by estimating individual fitness of roe deer (Capreolus capreolus) females in a population intensively monitored over $>30$ years.

\section{Model and individual fitness estimation}

12 To analyse longitudinal data on marked animals, we use a state-space formulation of MR models

13 (Gimenez et al. 2007; Royle 2008; Schofield and Barker 2008) that explicitly separates the

14 demographic process of interest, here being alive in a particular breeding state, from the

15 observations, i.e., the detection of animals (captures or sightings). Following Pradel's (2005)

16 notation, we assume that individuals move between a set of states $\left\{e_{1}, \ldots, e_{N}\right\}$ where $e_{1}$ stands for

17 being alive and non-breeding, $e_{\mathrm{N}}$ is the dead state and $e_{n}$ is for being alive with $n-1$ offspring $(n \neq$

$181, N)$. We denote $X_{i, t}$ the random state vector taking value 1 in the $n$-th position if, at time $t$,

19 individual $i$ is in state $e_{n}$, and 0 in the other positions. These states are only partially observed

20 through $L$ possible events $\left\{v_{1}, \ldots, v_{L}\right\}$ where $v_{1}$ stands for non-detected, $v_{2}$ detected with no

21 offspring and $v_{1}$ is for detected (captured or seen) with $l-2$ offspring $(l>2)$. We denote $Y_{i, t}$ the

22 random observation vector taking value 1 in the $l$-th position if, at time $t$, event $v_{1}$ happens to

23 individual $i$.

Our model includes several parameters. Let $\phi_{t}^{k \rightarrow k^{\prime}}$ be the probability that an individual alive

25 at time $t$ in state $e_{k}$ is alive at time $t+1$ in state $e_{k}$. It can be written as the product of survival $\varphi_{t}^{k}$ in 
1 state $e_{k}$ and transitions $\psi_{t}^{k \rightarrow k^{\prime}}$ between states $e_{k}$ and $e_{k^{\prime}}$. The matrix $\Phi_{t}$ gathers the probabilities $\phi_{t}^{k \rightarrow k^{\prime}}$

2 with states at time $t\left(e_{k}\right)$ in rows and those at time $t+1$ in columns $\left(e_{k^{\prime}}\right)$. We also define $b_{t}^{k l}$ the

3 probability that event $v_{1}$ happens to an individual in state $e_{k}$ at time $t$. The matrix $B_{t}$ gathers the

4 probabilities $b_{t}^{k l}$ with event $\left(v_{1}\right)$ in columns and states $\left(e_{k}\right)$ in rows at time $t$.

The state-space model relies on a combination of two processes. The state process specifies

6 the state of individuals at time $t+1$ given their state at time $t$ :

7

$$
X_{i, t+1} \mid X_{i, t} \sim \operatorname{multinomial}\left(1, X_{i, t} \Phi_{t}\right) \quad \text { Eq. } 1
$$

8

9 while the observation process specifies the observation of the individuals at time $t$ given their state

10 at time $t$ :

11

$$
Y_{i, t} \mid X_{i, t} \sim \text { multinomial }\left(1, X_{i, t} B_{t}\right)
$$

12

To fit this model and obtain posterior distributions of survival and transitions between breeding states, we used Markov chain Monte Carlo (MCMC) simulations in a Bayesian context (e.g., King et al. 2010).

The estimates of individual fitness were obtained for each of the three metrics. The $\lambda_{\text {ind }}$ were obtained as the dominant eigenvalue of a matrix built for each female (see Gaillard et al. 2000 for an application to the same roe deer population). This pre-breeding census matrix has, for each age $x$, the $f_{x} / 2$ value on its first row - where $f_{x}$ is the realized fecundity that is measured by the number of offspring produced at age $x$ that were successfully weaned - and 1 in its subdiagonal (McGraw and Caswell 1996). The LIC of each individual was calculated as the sum of the individual's annual 
1 contributions (Coulson et al. 2006). The annual contribution of a female $i$ to population growth

2 between $t$ and $t+1, P_{t(i)}$, is an individual's annual realized fitness, and was obtained as:

3

$$
P_{t(i)}=\frac{S_{t(i)}-\overline{S_{t}}}{N_{t}-1}+\frac{f_{t(i)}-\overline{f_{t}}}{N_{t}-1}
$$

5 where $S_{t(i)}$ is the survival for a female $i$ at time $t$ ( 1 if it survives, 0 otherwise); $\overline{S_{t}}$ is the mean

6 survival of all females in the population at time $t, f_{t(i)}$ is the realized fecundity for female $i$ at time $t$,

$7 \bar{f}_{t}$ is mean realized fecundity of all females in the population at time $t$, and $N_{t}$ is the population

8 size (females only) at time $t$. Lastly, the LRS was calculated as the number of offspring successfully

9 weaned by a female over its lifetime. The code to calculate the fitness metrics is available from

10 GitHub (https://github.com/oliviergimenez/estim_fitness).

11 The key here is to realize that, whenever a female is not detected, its number of offspring

12 cannot be measured. However, the state-space formulation in conjunction with the MCMC

13 machinery allows reconstructing the whole fate of any female $i$ by considering the reproductive

14 states $X_{i, t}$ as parameters to be estimated, just like the demographic parameters (e.g., Newman et al.

15 2006). At each MCMC step and for each female, age-specific numbers of weaned offspring are

16 obtained, a pre-breeding census matrix is built and its dominant eigenvalue is calculated to get a

17 value of $\lambda_{\text {ind }}$ and LRS. The same procedure is used for LIC. We assumed offspring survival between

18 weaning time and 1 year of age to be 1.

19

\section{Application to roe deer}


1 Data were collected on a population of roe deer in the enclosed forest of Trois Fontaines (1360 ha,

$248^{\circ} 43^{\prime} \mathrm{N}, 2^{\circ} 61^{\prime} \mathrm{E}$, North Eastern France). Animals were individually marked by ear-tags and

3 numbered collars. Each year since 1975, between 8 and 12 days of capture were organized between

4 December and March. Roe deer were captured by drive-netting, involving $150 \pm 30$ people and 2.5

$5 \mathrm{~km}$ of nets and resulting in the capture of 120-300 roe deer a year. Marked adult females (>2 years

6 of age, the age at first parturition in roe deer (Gaillard et al. 1992), were monitored in autumn

7 (October-December) to assess the number of fawns they successfully weaned in a given year (see

8 McLoughlin et al. 2007 for further details). Because early summer survival is the most critical stage

9 in roe deer (Gaillard et al. 2013), most fawns alive in late autumn are most likely to reach

10 adulthood. The number of fawns observed at heel in autumn was therefore used as a reliable

11 measure of annual reproductive success of a female. We measured reproductive success by the

12 number of fawns a given female successfully weaned (i.e., observed at heel), which included three

13 states ( 0,1 and 2 fawns). We only recorded a few instances (about $1.6 \%$ of records) of females

14 having 3 fawns at heel and pooled them with females observed with 2 fawns at heel. In total, we

15 used roe deer reproductive histories of 271 females that were monitored between 1977 and 2011.

16 We considered four states, $e_{1}=$ 'alive non-breeder', $e_{2}=$ 'alive and breeder with one fawn', $e_{3}=$

17 'alive and breeder with two fawns', $e_{4}=$ 'dead'. Based on the roe deer life history (e.g., Gaillard et

18 al. 1998), we considered several possible observations that were generated from these underlying

19 states as $v_{1}=$ 'the animal is not seen', $v_{2}=$ 'the animal is seen without any fawn', $v_{3}=$ 'the animal is

20 seen with one fawn', $v_{4}=$ 'the animal is seen with two fawns'. Age-dependence in $\varphi_{t}^{k}$ was

21 modelled using two classes: prime-aged (2 to 7 years) and old adults (8 years and older). Given that

22 an individual is alive in a given state, it can survive and remain in the same state (terms in

23 diagonal), survive and move to another state (off-diagonal terms), or die (last column). If an

24 individual is dead, it remains dead (last row). Hence, we used: 


$$
\Phi_{t}=\left[\begin{array}{cccc}
\phi^{e_{1}} \psi^{e_{1} \rightarrow e_{1}} & \phi^{e_{1}} \psi^{e_{1} \rightarrow e_{2}} & \phi^{e_{1}} \psi^{e_{1} \rightarrow e_{3}} & 1-\phi^{e_{1}} \\
\phi^{e_{2}} \psi^{e_{2} \rightarrow e_{1}} & \phi^{e_{2}} \psi^{e_{2} \rightarrow e_{2}} & \phi^{e_{2}} \psi^{e_{2} \rightarrow e_{3}} & 1-\phi^{e_{2}} \\
\phi^{e_{3}} \psi^{e_{3} \rightarrow e_{1}} & \phi^{e_{3}} \psi^{e_{3} \rightarrow e_{2}} & \phi^{e_{3}} \psi^{e_{3} \rightarrow e_{3}} & 1-\phi^{e_{3}} \\
0 & 0 & 0 & 1
\end{array}\right]
$$

Eq. 4

2 Regarding the observation process, we specify that, given that an individual is alive in state non-

3 breeder or breeder, it can be missed (first column) or controlled as a non-breeder or breeder

4 respectively. Besides, given that an individual is dead, it is missed with certainty (last row). We

5 therefore used:

6

$$
B_{t}=\left[\begin{array}{cccc}
1-p_{t}^{e_{1}} & p_{t}^{e_{1}} & 0 & 0 \\
1-p_{t}^{e_{2}} & 0 & p_{t}^{e_{2}} & 0 \\
1-p_{t}^{e_{3}} & 0 & 0 & p_{t}^{e_{3}} \\
1 & 0 & 0 & 0
\end{array}\right]
$$

8 where we considered the probability $p_{t}^{e_{k}}$ that an individual $i$ is detected at time $t$ in state $e_{k}$ (same

9 probability for all breeder individuals). Uncertainty in assessing the breeding status was not due to

10 the issue of detection only. If a female was detected in the field, its breeding status did not

11 correspond necessarily to the observation made. For example, if a female was observed with no

12 fawn, it actually might be in state $e_{2}$ or $e_{3}$ just because its fawns were not with it when it was

13 detected. We incorporated uncertainty in state assignment in the calculation of individual fitness by

14 adding probabilities of state assignment on top of the detection process (Pradel 2005; Gimenez et al.

15 2012). The observation matrix in Eq. 4 was modified consequently: 


$$
B_{t}=\left[\begin{array}{ccccc}
1-p_{t}^{e_{1}} & p_{t}^{e_{1}} \delta & 0 & 0 & p_{t}^{e_{1}}(1-\delta) \\
1-p_{t}^{e_{2}} & 0 & p_{t}^{e_{2}} \delta^{\prime} & 0 & p_{t}^{e_{2}}\left(1-\delta^{\prime}\right) \\
1-p_{t}^{e_{3}} & 0 & 0 & p_{t}^{+} \delta^{\prime} & p_{t}^{e 3}\left(1-\delta^{\prime}\right) \\
1 & 0 & 0 & 0
\end{array}\right]
$$

Eq. 6

2 in which we added the new event 'breeding state not ascertained' (last column) that could arise for

3 non-breeders (first row) as well as breeders (second and third rows), though with potentially

4 different probabilities: a non-breeder was assumed to be judged as a non-breeder with probability $\delta$

5 while a breeder was assumed to be judged as a breeder with probability $\delta$.

6 A preliminary analysis (see Table S1 in Electronic Supplementary Material) suggested that a model

7 including i) a survival probability varying over age and breeding status, ii) breeding status-specific

8 detection probabilities and iii) constant-over-age transition probabilities between reproductive

9 statuses was well supported by the data. We used the software JAGS (Plummer 2003) to fit this

10 model to the MR female roe deer data in a Bayesian framework. Uniform prior distributions were

11 used for all parameters. We ran two MCMC chains with a burn-in period of 5000 iterations

12 followed by 20,000 iterations on which we based our inference. We checked convergence visually

13 by inspecting the chains and by checking that the R-hat statistic was below 1.1 . The code to fit the

14 model is available from GitHub (https://github.com/oliviergimenez/estim_fitness).

\section{Results}

18 We found strong heterogeneity in detection due to the reproductive status (Table 1), with detection

19 rate for breeders $p_{2}^{e}=e_{3}$ equal to $0.92(\mathrm{SD}=0.05)$ vs. that of non-breeders $p_{1}^{e}$ equal to only $0.53(\mathrm{SD}$

$20=0.03)$. As expected, survival of old females $\left(0.69(\mathrm{SD}=0.64)\right.$ for non-breeders $\not{ }^{e}(\mathrm{o})$ and 0.83

$21(\mathrm{SD}=0.05)$ for breeders $\left.\phi_{2}^{e}=e_{3}(\mathrm{o})\right)$ was lower than that of prime-aged females $(0.84(\mathrm{SD}=0.02)$ for 
1 non-breeders $\not{ }^{e}(\mathrm{pa})$ and $0.97(\mathrm{SD}=0.02)$ for breeders $\left.\phi_{2} e_{2}=e_{3}(\mathrm{pa})\right)$, regardless of their breeding

2 status (Table 1$)$. The probability of correct assignment for breeders $\delta(0.93, \mathrm{SD}=0.05)$ was much 3 higher than that for non-breeders $\delta(0.26, \mathrm{SD}=0.02)$.

4
[TAB. 1 AROUND HERE]

The distribution of individual fitness was far from normal for LRS (Fig. 1a), bimodal for $\lambda_{\text {ind }}$ with two groups of individuals (Fig. 1b), one with main value of fitness centred on around 0.1 and the other on 1.4 and symmetric for LIC (Fig. 1c).

[FIG. 1 AROUND HERE]
.

\section{Discussion}

In this work, we have extended the estimation of standard individual fitness metrics to account for imperfect detection. By reconstructing the whole life history, our approach allows the use of every individual even though some reproductive events were not recorded. Besides, by allowing the simultaneous estimation of demographic parameters and individual fitness, our approach can be combined with the tools developed in the MR literature to explore individual (Royle 2008; Gimenez and Choquet 2010) and environmental (Grosbois et al. 2008) variability in demographic parameters, and how this translates to variation in individual fitness. Last, an alternative approach - the Viterbi algorithm - exists in the Frequentist framework (Rouan et al. 2009) to find the most probable path of breeding states for each individual. However, in contrast with the Bayesian approach, the Viterbi algorithm does not easily allow propagating sampling uncertainty in the demographic parameter estimates to the fitness metrics estimates. A limitation of our approach is when individuals have 
1 many offspring (e.g., fishes), which requires extending the number of breeding states. This, in turn,

2 comes with an exponential increase in the number of transition probabilities, which might hamper

3 parameter estimation. If the focus of the analysis is in estimating fitness and not necessarily in

4 making inference about the transition probabilities, then a solution to the issue of many states is to

5 allocate states to bins of some length and use the midpoint of these intervals as new states to reduce

6 the state space (Zucchini et al. 2016; Cowen et al. 2017 for an application).

From a more biological viewpoint, this new statistical approach applied to the long-term monitoring of female reproductive success in an intensively studied population of roe deer gave support for some previous findings but also provided new information.

The marked differences in detection probability between successful and unsuccessful

11 females highlighted by the analyses correspond to a key finding that has not been yet reported in roe 12 deer. However, the higher detection probability for successful females compared to unsuccessful 13 females could be expected to occur in ungulates in relation to the much higher activity of lactating 14 females, especially foraging activity (Neuhaus and Ruckstuhl 2002 in Alpine Ibex Capra ibex, 15 Hamel and Côté 2008 in Mountain Goat Oreamnos Americana, Ruckstuhl and Neuhaus 2002 for a 16 review). Roe deer females allocate a lot to reproduction at each breeding attempt by producing two 17 fawns that are large at birth and grow fast during the weaning period (Gaillard et al. 1993). 18 Moreover, roe deer females are income breeders (Andersen et al. 2000), which do rely on available 19 resources rather than on body reserves to meet the high-energy expenditure they allocate to 20 reproduction. Thus, successful females have to forage most of their time to find abundant and rich 21 food, whereas barren females or females that lost their fawns right after birth have much lower 22 energy requirements and are expected to be much less active. A marked increased activity of roe 23 deer females with fawns at heel, which matches with an increase in metabolic rate (by $27 \%$, Mauget 24 et al. 1997), is thus likely to cause the almost twofold increase in detection probability of breeding 25 females compared to non-breeding females we report here. 
In addition of being easier to detect, females with fawns at heel survived better than females

2 that failed weaning any fawn in a given year. Such a positive association between reproductive success and subsequent survival supports previous analyses of reproductive trajectories performed

4 in the same population (Plard et al. 2012) and demonstrates the existence of a strong among-female

5 variation in demographic performance and the absence of a detectable trade-off between current

6 reproduction and future performance, as it has often been reported in vertebrate populations (see

7 e.g., Cam et al. 2002 on Kittiwakes Rissa tridactyla, Barbraud and Weimerskirch 2005 on Blue petrel Halobaena caerulea, Beauplet et al. 2006 on Subantarctic fur seal Arctocephalus tropicalis,

9 Le Bohec et al. 2007 on King penguin Aptenodytes patagonicus, Weladji et al. 2008 on Reindeer

10 Rangifer tarandus, Maniscalco et al. 2010 on Steller sea lion Eumatopias jubatus). This positive

11 association between current reproduction and subsequent survival indicates that individual variation

12 in resource acquisition is larger than individual variation in resource allocation (van Noordwijk and 13 de Jong 1986). Variation in resource acquisition among individuals is often interpreted in terms of 14 individual quality (sensu Wilson and Nussey 2010). Under this concept, individuals can be ranked 15 along a high-low demographic performance continuum. However, what causes the position of 16 individuals on this continuum is subjected to debate (Tuljapurkar et al. 2009; Cam et al. 2016).

17 Several factors are likely interplaying to shape the distribution of individuals among successful vs. unsuccessful trajectories. In roe deer females, the home range quality in terms of food resources seems to play a key role. Thus, females having access to meadows during the critical fawn rearing period raised twice more offspring than other females (McLoughlin et al. 2007) and fawns whose 21 mother home range included hornbeam (Carpinus betula) survived much better than fawns born in 22 areas without hornbeam (Pettorelli et al. 2005). Interestingly, we did not detect any association between previous and future reproduction. Previous studies of vertebrate populations have often

24 reported some association, although varying in direction. For instance, Morano et al. (2013) reported a negative influence of recruiting an offspring on the pregnancy rate in the subsequent 
1 breeding season in elk (Cervus elaphus canadensis) and Stoelting et al. (2014) found that breeding

2 in a given year reduced the probability of reproducing the year after in California spotted owl (Strix

3 occidentalis occidentalis), whereas Blomberg et al. (2013) and Hernández-Matías et al. (2011)

4 reported a positive association between reproductive success over two consecutive years in Greater

5 sage grouse (Centrocercus urophasianus) and Bonelli's eagle (Aquila fasciata), respectively. For

6 income breeders such as roe deer females, a positive rather than negative association is expected

7 because of the absence of accumulated body reserves, which provide a functional link between consecutive reproductive attempts in capital breeders. However, the reproductive success of roe deer is highly dependent on the immediate availability of food resources in spring (Gaillard et al.

10 2013). Strong yearly variation in food resources caused by variable weather conditions, which has

11 not been accounted for in the present analysis, is likely to explain this lack of association between

12 consecutive reproductive attempts. Such findings differ from previous analyses of reproductive roe 13 deer trajectories in that population. Indeed, Plard et al. (2012) found that a female that weaned two

14 fawns in a given year had a probability to wean again two fawns the year after more than twice that 15 of failing to wean any fawn. On the other hand, females that failed to wean any fawn in a given year 16 had equal probability to fail again, wean only one fawn, or wean two fawns. The discrepancy might 17 be explained by the much lower detection probability of females without fawns at heel, which is controlled for in the present study but was not in Plard et al.'s (2012) analysis.

The three metrics of individual fitness we estimated in roe deer females all displayed a marked deviation from a normal distribution. Compared to the normal distribution, the observed

21 distribution of LRS, individual growth rates and individual contributions all indicated a much larger 22 variation in fitness among females, a finding supporting a previous result reported from a much 23 lower sample size of females intensively monitored for 5 years (Gaillard et al. 1998). On the other 24 hand, the ratio between successful and unsuccessful females markedly differed between the present 25 analysis and our previous study. While only 5 out of 37 females were highly unsuccessful in 
1 Gaillard et al. (1998) of 5-year reproductive success between 1978 and 1995 (see Fig. 4 p. 2884),

2 more than half of females were highly unsuccessful in terms of LRS between 1977 and 2011 in the 3 present study (see Fig. 1a). Although environmental conditions have worsened a lot over time in the 4 study site (Gaillard et al. 2013), a high proportion of unsuccessful females were also observed 5 before 1995 in this analysis. Not accounting for the lower detection rate of unsuccessful females 6 likely led to overestimate the overall population recruitment. However, the discrepancy is also 7 likely overestimated by markedly different assessment of LRS. In the first study, LRS was inferred from annual reproductive success during the first 5 years with available data for a given female. On

9 the other hand, in the present study, LRS was inferred from a markedly different number of 10 reproductive attempts across females.

11 The distributions of individual fitness suggest that the population studied should be better 12 viewed as a mixture of good (or robust) and poor (or frail) females with some individuals displaying 13 intermediate performance than as a continuous distribution. This has important consequences for 14 modelling individual heterogeneity in wild populations. While the use of random effect models 15 assuming a normal distribution of individual differences in the focal trait has become the rule (van 16 de Pol and Verhulst 2006; van de Pol and Wright 2009), our detailed analysis or life history 17 trajectories clearly indicates that the distribution of individual performance markedly deviates from 18 a normal distribution, and rather exhibits a bimodal distribution that should be better captured by 19 mixture models (Hamel et al. 2017). In support, a recent comparative analysis of individual 20 heterogeneity in adult survival across a selected set of mammal and bird species has shown that a 21 mixture models including two classes of individuals (i.e., frail vs. robust) consistently provided a 22 better fit to observed data than random effect models based on a normal distribution of individual 23 performance (Péron et al. 2016). The new statistical approach we propose to estimate the distribution of fitness among 25 individuals within a given population where individual reproductive success can be assessed by 
1 observations of mother-offspring associations allows accounting for both imperfect detection and

2 differences in detection probability among individuals with different reproductive status. The

3 application to roe deer females in an intensively monitored population demonstrates the potential of

4 this approach. In particular, this analysis suggests that previous analyses of fitness distribution

5 assessed from observed life histories trajectories are likely to have over-estimated the average

6 individual fitness, and thereby the population growth rate (Fisher 1930) because of the expected

7 lower detection probability of unsuccessful individuals. Such biases have obvious negative 8 consequences in a management or conservation context. We thus urge future studies to account for

9 both imperfect detection and differences in detection probability among individuals with different

10 reproductive status in order to provide reliable estimates of individual fitness and of its distribution

11 at the level of the population.

13 Acknowledments

15 This is a contribution of the GDR Statistical Ecology. OG was supported by the French National

16 Research Agency with a grant ANR-16-CE02-0007.

References

20 Andersen R, Gaillard JM, Linnell JDC, Duncan P (2000) Factors affecting maternal care in an income breeder, the European roe deer. J Anim Ecol 69:672-682

Barbraud C, Weimerskirch H (2005) Environmental conditions and breeding experience affect costs of reproduction in Blue Petrels. Ecology 86:682-692

24 Beauplet G, Barbraud C, Dabin W, Küssener C, Guinet C, Benton T (2006) Age-specific survival and reproductive performances in fur seals: Evidence of senescence and individual quality. 
Blomberg EJ, Sedinger JS, Nonne DV, Atamian MT (2013) Seasonal reproductive costs contribute to reduced survival of female greater sage-grouse. J Avian Biol 44:149-158

Brommer JE, Merilä J, Kokko H (2002) Reproductive timing and individual fitness. Ecol Lett $5: 802-810$

Brommer JE, Gustafsson L, Pietiäinen H, Merilä J (2004) Single-generation estimates of individual fitness as proxies for long-term genetic contribution. Am Nat 163:505-517

Cam E, Link WA, Cooch EG, Monnat JY, Danchin E (2002) Individual covariation in life-history traits: seeing the trees despite the forest. Am Nat 159:96-105

Cam E, Aubry LM, Authier M (2016) The conundrum of heterogeneities in life history studies. Trends Ecol Evol 31:872-886

Clutton-Brock TH (1988) Reproductive success. Studies of individual variation in contrasting breeding systems. University of Chicago Press, Chicago, USA

Coulson T, Benton TG, Lundberg P, Dall SR, Kendall BE, Gaillard JM (2006) Estimating 5 individual contributions to population growth: evolutionary fitness in ecological time. Proc R Soc B Biol Sci 273:547-555

Cowen LLE, Besbeas P, Morgan BJT, Schwarz CJ (2017) Hidden Markov Models for extended batch data. Biometrics. In press

Cubaynes S, Pradel R, Choquet R, Duchamp C, Gaillard JM, Lebreton JD, Marboutin E, Miquel C, Reboulet AM, Poillot C, Taberlet P, Gimenez O (2010) Importance of accounting for detection heterogeneity when estimating abundance: the case of French wolves. Conserv Biol 24:621626 
1 Gaillard JM, Sempere AJ, Boutin JM, Van Laere G, Boisaubert B (1992) Effects of age and body

Gaillard JM, Delorme D, Jullien JM (1993) Effects of cohort, sex, and birth date on body development of roe deer (Capreolus capreolus) fawns. Oecologia 94:57-61

Gaillard JM, Andersen R, Delorme D, Linnell JDC (1998) Family effects on growth and survival of juvenile roe deer. Ecology 79:2878-2889

Gaillard JM, Festa-Bianchet M, Delorme D, Jorgenson J (2000) Body mass and individual fitness in female ungulates: bigger is not always better. Proc R Soc B Biol Sci 267:471-477

Gaillard JM, Mark Hewison AJ, Klein F, Plard F, Douhard M, Davison R, Bonenfant C (2013) How does climate change influence demographic processes of widespread species? Lessons from the comparative analysis of contrasted populations of roe deer. Ecol Lett 16:48-57

Gimenez O, Choquet R (2010) Individual heterogeneity in studies on marked animals using numerical integration: capture-recapture mixed models. Ecology 91:951-957

Gimenez O, Rossi V, Choquet R, Dehais C, Doris B, Varella H, Vila JP, Pradel R (2007) Statespace modelling of data on marked individuals. Ecol Model 206:431-438

Gimenez O, Viallefont A, Charmantier A, Pradel R, Cam E, Brown CR, Anderson MD, Brown MB, Covas R, Gaillard JM (2008) The risk of flawed inference in evolutionary studies when detectability is less than one. Am Nat 172:441-448

Gimenez O, Lebreton JD, Gaillard JM, Choquet R, Pradel R (2012) Estimating demographic parameters using hidden process dynamic models. Theor Popul Biol 82:307-316

Grosbois V, Gimenez O, Gaillard JM, Pradel R, Barbraud C, Clobert J, Møller AP, Weimerskirch H (2008) Assessing the impact of climate variation on survival in vertebrate populations. Biol Rev 83:357-399 
1 Hamel S, Côté SD (2008) Trade-offs in activity budget in an alpine ungulate: contrasting lactating and nonlactating females. Anim Behav 75:217-227

Hamel S, Yoccoz NG, Gaillard JM (2017) Assessing variation in life-history tactics within a population using mixture regression models: a practical guide for evolutionary ecologists. Biol Rev 92:754-775

Hamilton WD (1966) The moulding of senescence by natural selection. J Theor Biol 12:12-45

Hernández-Matías A, Real J, Pradel R, Ravayrol A, Vincent-Martin N (2011) Effects of age, territoriality and breeding on survival of Bonelli's Eagle Aquila fasciata. Ibis 153:846-857

Lebreton JD, Nichols JD, Barker RJ, Pradel R, Spendelow JA (2009) Modeling individual animal

Käär P, Jokela J (1998) Natural selection on age-specific fertilities in human females: comparison of individual-level fitness measures. Proc R Soc B Biol Sci 265:2415-2420

King R, Morgan BJT, Gimenez O, Brooks SP (2010) Bayesian Analysis for population ecology. Chapman \& Hall/CRC, Boca Raton, USA

Korpelainen H (2000) Fitness, reproduction and longevity among European aristocratic and rural Finnish families in the 1700s and 1800s. Proc R Soc B Biol Sci 267:1765-1770

Lahdenpera M, Lummaa V, Helle S, Tremblay M, Russell AF (2004) Fitness benefits of prolonged post-reproductive lifespan in women. Nature 428:178-181

Le Bohec C, Gauthier-Clerc M, Gremillet D, Pradel R, Béchet A, Gendner JP, Le Maho Y (2007) Population dynamics in a long-lived seabird: I. Impact of breeding activity on survival and breeding probability in unbanded king penguins. J Anim Ecol 76:1149-1160

Lebreton JD, Burnham KP, Clobert J, Anderson DR (1992) Modeling survival and testing biological hypotheses using marked animals: a unified approach with case studies. Ecol Monogr 62:67-118 histories with multistate capture-recapture models. Adv Ecol Res 41:87-173 
1 Lenski RE, Service PM (1982) The statistical analysis of population growth rates calculated from

Mauget C, Mauget R, Sempéré AJ (1997) Metabolic rate in female European roe deer (Capreolus capreolus): Incidence of reproduction. Can J Zool Can Zool 75:731-739

McGraw JB, Caswell H (1996) Estimation of individual fitness from life-history data. Am Nat 147:47-64

McLoughlin PD, Gaillard JM, Boyce MS, Bonenfant C, Messier F, Duncan P, Delorme D, Moorter BV, Saïd S, Klein F (2007) Lifetime reproductive success and composition of the home range in a large herbivore. Ecology 88:3192-3201

Moorad JA (2013) A demographic transition altered the strength of selection for fitness and agespecific survival and fertility in a 19th century American population. Evolution 67:1622-1634

Morano S, Stewart KM, Sedinger JS, Nicolai CA, Vavra M (2013) Life-history strategies of North American elk: trade-offs associated with reproduction and survival. J Mammal 94:162-172

Neuhaus P, Ruckstuhl KE (2002) Foraging behaviour in Alpine ibex (Capra ibex): consequences of reproductive status, body size, age and sex. Ethol Ecol Evol 14:373-381

Newman KB, Buckland ST, Lindley ST, Thomas L, Fernández C (2006) Hidden process models for animal population dynamics. Ecol Appl 16:74-86

Newton I (1989) Lifetime reproduction in birds. Academic Press, London, UK

Nichols JD (1992) Capture-Recapture Models. Bioscience 42:94-102

Péron G, Gaillard JM, Barbraud C, Bonenfant C, Charmantier A, Choquet R, Coulson T, Grosbois 

V, Loison A, Marzolin G, Owen-Smith N, Pardo D, Plard F, Pradel R, Toïgo C, Gimenez O (2016) Evidence of reduced individual heterogeneity in adult survival of long-lived species. Evolution 70:2909-2914

Pettorelli N, Gaillard JM, Yoccoz NG, Duncan P, Maillard D, Delorme D, Van Laere G, Toïgo C (2005) The response of fawn survival to changes in habitat quality varies according to cohort quality and spatial scale. J Anim Ecol 74:972-981

Plard F, Bonenfant C, Delorme D, Gaillard JM (2012) Modeling reproductive trajectories of roe deer females: Fixed or dynamic heterogeneity? Theor Popul Biol 82:317-328

Plummer M (2003) JAGS: A program for analysis of Bayesian graphical models using Gibbs sampling. In: Hornik K, Leisch F, Zeileis A (eds) Proceedings of the 3rd International Workshop on Distributed Statistical Computing, March 20-22, Vienna, Austria

Pradel R (2005) Multievent: an extension of multistate capture-recapture models to uncertain states. Biometrics 61:442-447

Rose KE, Clutton-Brock TH, Guinness FE (1998) Cohort variation in male survival and lifetime breeding success in red deer. J Anim Ecol 67:979-986

Rouan L, Gaillard JM, Guédon Y, Pradel R (2009) Estimation of lifetime reproductive success when reproductive status cannot always be assessed. In: Thomson DL, Cooch EG, Conroy MJ (eds) Modeling demographic processes in marked populations. Springer, USA, pp 867-879

Royle JA (2008) Modeling individual effects in the Cormack-Jolly-Seber model: a state-space formulation. Biometrics 64:364-370

Ruckstuhl KE, Neuhaus P (2002) Sexual segregation in ungulates: a comparative test of three hypotheses. Biol Rev 77:77-96

Schofield MR, Barker RJ (2008) A unified capture-recapture framework. J Agric Biol Environ Stat $13: 458-477$ 
1 Stoelting RE, Gutiérrez RJ, Kendall WL, Peery MZ (2014) Life-history tradeoffs and reproductive cycles in Spotted Owls. Auk 132:46-64

3 Tuljapurkar S, Steiner UK, Orzack SH (2009) Dynamic heterogeneity in life histories. Ecol Lett $12: 93-106$

van de Pol M, Verhulst S (2006) Age-dependent traits: a new statistical model to separate withinand between-individual effects. Am Nat 167:766-773

van de Pol M, Wright J (2009) A simple method for distinguishing within-versus between-subject effects using mixed models. Anim Behav 77:753-758

van Noordwijk AJ, de Jong G (1986) Acquisition and allocation of resources: Their influence on variation in life history tactics. Am Nat 128:137-142

11 Weladji RB, Loison A, Gaillard JM, Holand O, Mysterud A, Yoccoz NG, Nieminen M, Stenseth NC (2008) Heterogeneity in individual quality overrides costs of reproduction in female 3 reindeer. Oecologia 156:237-247

Wilson AJ, Nussey DH (2010) What is individual quality? An evolutionary perspective. Trends Ecol Evol 25:207-214

Zucchini W, MacDonald IL, Langrock R (2016) Hidden Markov Models for time series: An 
$1 \quad$ Figure legends

2

3 Fig. 1 Capture-recapture estimates of fitness metrics for roe deer: a) lifetime reproductive fitness

4 (bar plot), b) individual fitness (kernel density estimate) and c) lifetime individual contribution 5 (kernel density estimate).

6

7 
1 Tab. 1 Parameter estimates with $95 \%$ credible intervals.

posterior mean estimate

parameter

(standard deviation)

\begin{tabular}{|c|c|}
\hline detection of breeders $p_{2}^{e}=e_{3}$ & $0.92(0.05)$ \\
\hline detection of non-breeders $p^{e} 1$ & $0.53(0.03)$ \\
\hline survival of prime-age non-breeders $\phi_{1}^{e}(\mathrm{pa})$ & $0.84(0.02)$ \\
\hline survival of old non-breeders $\not{ }^{e}(\mathrm{o})$ & $0.69(0.04)$ \\
\hline survival of prime-age breeders $\phi_{2}^{e}=e_{3}(\mathrm{pa})$ & $0.97(0.02)$ \\
\hline survival of old breeders $\phi_{1}(\mathrm{o})$ & $0.83(0.05)$ \\
\hline transition non-breeder to 1 fawn $\psi_{1}^{e} \rightarrow e_{2}$ & $0.13(0.02)$ \\
\hline transition non-breeder to 2 fawns $\psi^{e}{ }_{1} \rightarrow e_{3}$ & $0.12(0.02)$ \\
\hline transition 1 fawn to non-breeder $\psi_{2}^{e} \rightarrow e_{1}$ & $0.54(0.06)$ \\
\hline transition 1 to 2 fawns $\psi_{2}^{e} \rightarrow e_{3}$ & $0.25(0.04)$ \\
\hline transition 2 fawns to non-breeder $\psi^{e}{ }_{3} \rightarrow e_{1}$ & $0.49(0.05)$ \\
\hline transition 2 to 1 fawn $\psi^{e}{ }_{3} \rightarrow e_{2}$ & $0.34(0.04)$ \\
\hline proportion of non-breeders $\pi^{e}{ }_{1}$ & $0.64(0.04)$ \\
\hline proportion of females with 1 fawn $\pi^{e}{ }_{2}$ & $0.15(0.03)$ \\
\hline Assignment $\delta$ & $0.26(0.02)$ \\
\hline Assignment $\delta$ & $0.93(0.05)$ \\
\hline
\end{tabular}


a) Lifetime reproductive success (LRS)

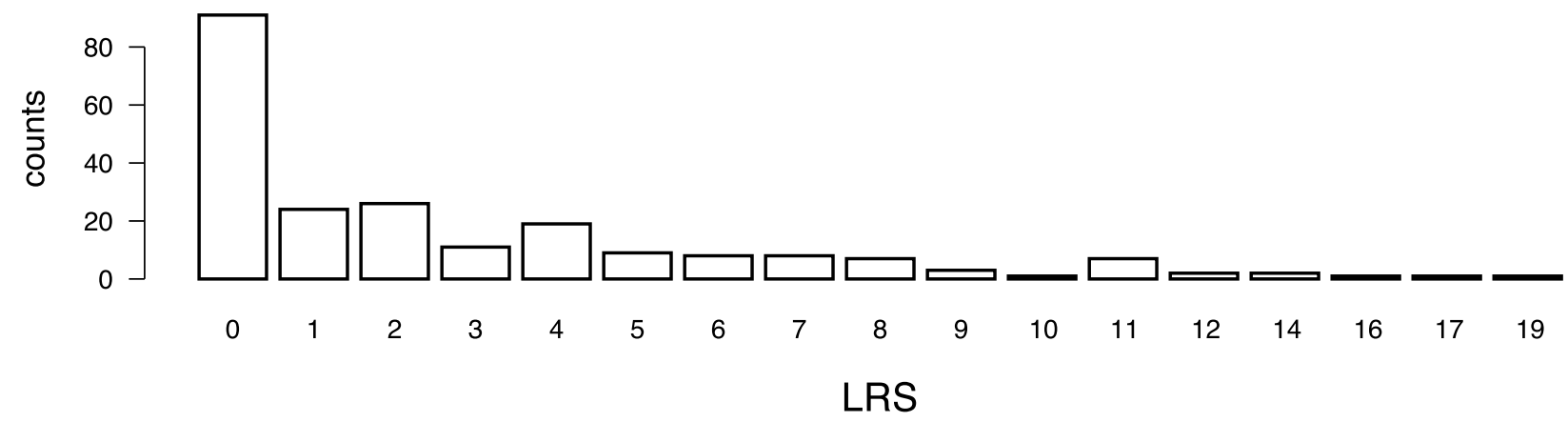

b) Individual fitness $\left(\lambda_{\text {ind }}\right)$

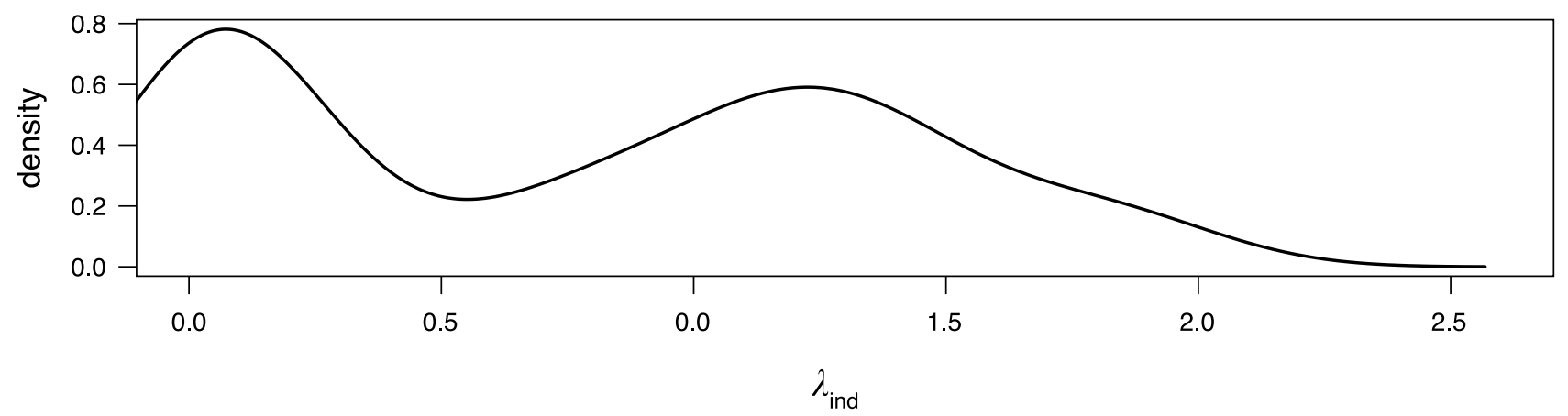

c) Lifetime individual contribution (LIC)

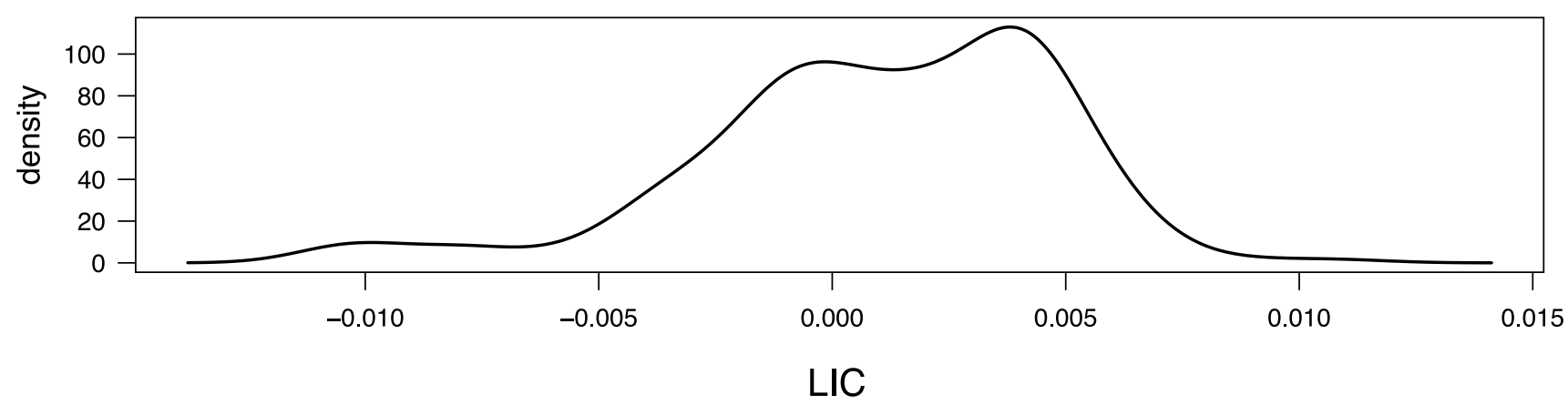


a) Lifetime reproductive success (LRS)

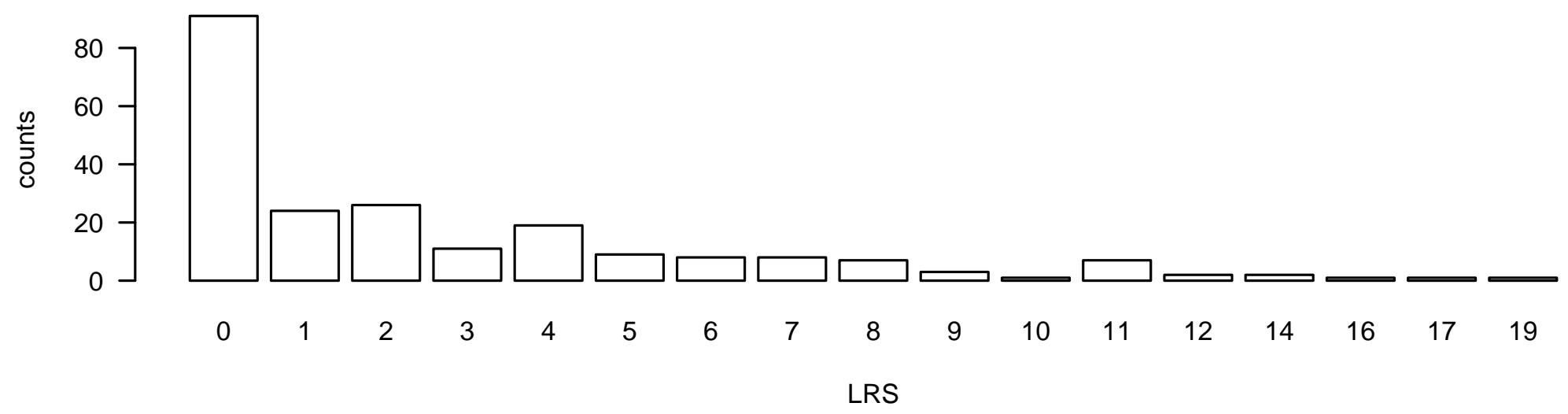

b) Individual fitness $\left(\lambda_{\text {ind }}\right)$

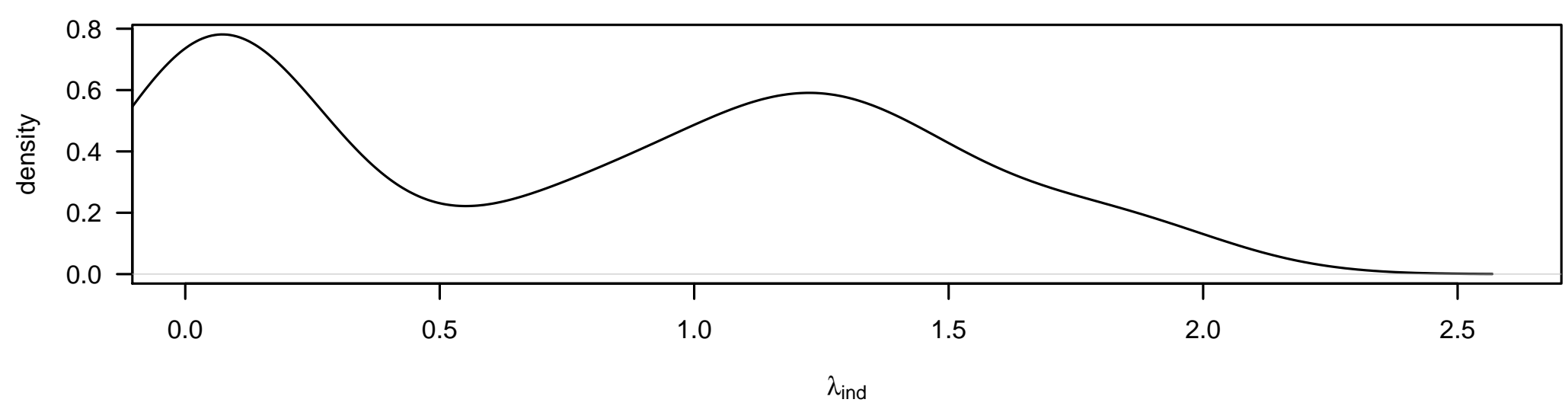

c) Lifetime individual contribution (LIC)

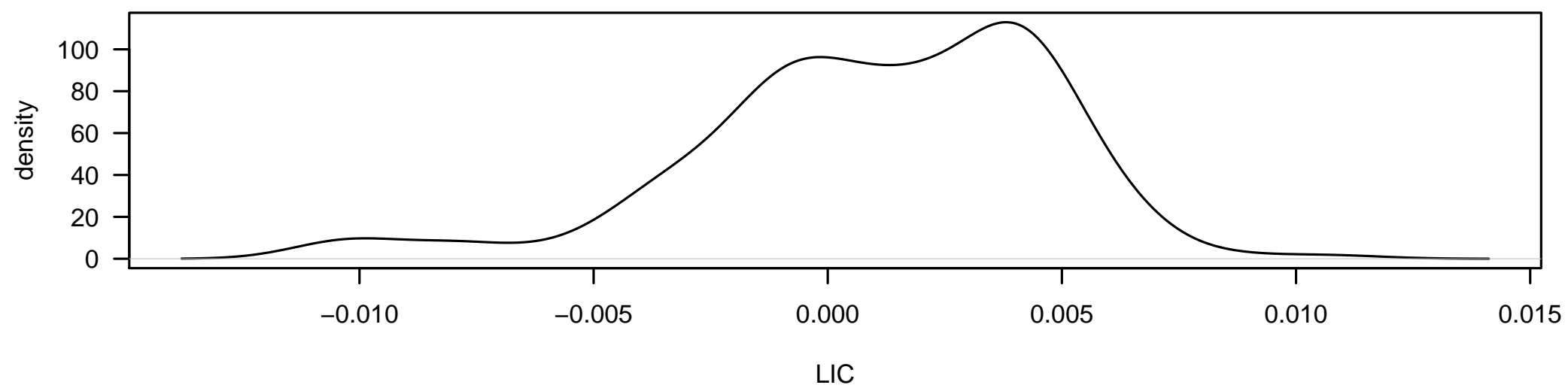

